\title{
Cost Management of Retail Enterprises under the New Retail Format
}

\author{
Chonghao Tang*
}

Zhejiang University of Finance \& Economics Dongfang College, Jiaxing 314499, China, E-mail: 987670598@qq.com

Abstract: With the acceleration of the digitalization process, new retail is also emerging. With its convenient and flexible operation mode, new retail has become the trend of the current traditional retail industry transformation, and it is an inevitable choice for retail enterprises to achieve sustainable and healthy development. Based on the actual situation, this article analyzes some cost management problems which new retail enterprises are facing, and then proposes corresponding solutions to provide reference suggestions for the development of new retail enterprises.

Keywords: New Retail; Enterprise; Cost; Management

\section{Introduction}

With the advent of the era of big data, the development of the traditional retail industry with the goal of maximizing enterprise value is threatened, and the supply chain model that promotes consumer demand through production needs to be changed. In October 2016, Jack Ma delivered a wonderful speech at the Yunqi Conference and put forward the concept of new retail for the first time. He believed that "In the next ten years, pure e-commerce will decline, and new retail will be replaced by it". In the future, the application of new technologies will continue to promote the development of new retail, making management easier, making services more humane, and making consumer experience better.

\section{Status of new retail industry}

At present, domestic giant companies include Alibaba, Tencent, Baidu, JD.com, Xiaomi, and NetEase have "tested the waters" of this new industry. Among them, the better-developed ones include Ali Group's "Hema Xiansheng", Xiaom's "Xiaomi Home", and NetEase's "NetEase Yanxuan" "[1]. Through research, it can be found that these new retail companies have a common characteristic. They all founded and developed with the support of big data analysis and AI technology. To the greater extent that data sharing between online e-commerce and offline entities can satisfy consumers' huge demands for customization, personalization and diversification. At the same time, companies will also achieve higher logistics efficiency through self-built logistics or third-party logistics, so as to bring customers the ultimate consumption experience ${ }^{[2]}$. However, the operation of a company cannot escape the cost management problem after all. The establishment of a new retail model requires more cost input. How to manage and control costs to expand the profit margin of the company is a major issue that new retail companies need to solve urgently ${ }^{[3]}$.

\section{Cost management problems of new retail enterprises}

At this stage, in the development process of the new retail industry, both the offline involvement of online e-commerce and the online development of physical retail will encounter related cost management problems, which mainly focus on three aspects of system: construction, talent recruitment and management, corporate capital investment, and logistics.

This is an open-access article distributed under the terms of the Creative Commons Attribution Non-Commercial License (http://creativecommons.org/licenses/by-nc/4.0/), which permits unrestricted non-commercial use, distribution, and reproduction in any medium, provided the original work is properly cited. 


\subsection{High demand for high-quality talents leads to high labor costs}

Most new retail companies are currently in a period of rapid expansion, and they need to acquire more users in a relatively short period of time. However, rapid expansion not only expands the scale of the enterprise, but also places higher demands on employees and product management. At present, there are still major problems in the management of employees, training and development, and the establishment of norms and standards for new retail companies ${ }^{[4]}$. Cultivating a large number of high-quality talents, while improving benefits to retain high-end compound management talents is the key to achieve the successful development of new retail companies. But to meet such demand for talents, companies must invest a lot of labor costs. In 2020, which is deeply affected by the epidemic, the demand for talents in the new retail industry has not only not decreased but increased substantially ${ }^{[5]}$. The average recruitment salary for new retail positions is 11,488 yuan/month, which is higher than the industry average salary and 1.3 times the national average; It is $20 \%-30 \%$ higher than the salary of traditional industry positions. [Data source: "2020 New Retail Industry Talent Report" released by Zhaolian Recruitment and Intime Department Store From these data, it can be seen that the labor cost burden which new retail companies are facing will continue to increase.

\subsection{Large initial capital investment leads to high operating costs}

New retail companies need to invest high costs to open offline physical stores, build online e-commerce and develop new logistics. The investment of large amounts of resources will undoubtedly increase the cost burden for new retail companies. Every commodity and every transaction online is actually an interactive process of the cloud system; while offline, there are a large number of offline operations. Because the infrastructure of offline physical stores is relatively backward, a large number of transformations have been carried out, and the maintenance costs in the later period also cannot be underestimated. Therefore, integrating a large number of physical stores into an online system is an important issue that companies have to face. At present, the reason why many new retail companies are at a loss is that they fail to afford high operating costs ${ }^{[6]}$.

\subsection{Imperfect logistics system leads to high logistics costs}

Labor costs, warehousing costs, transportation costs, circulation costs and processing costs are the five major components of the international standard logistics industry cost. Compared with European and American countries, transportation costs and storage costs are higher in China. From the perspective of transportation, the modern European and American logistics system represented by Wal-Mart, through one-stop distribution services, can directly deliver goods to the destination at one time, saving a lot of intermediate costs. In our country, cargo transportation often needs to be carried out in batches, the process is cumbersome, the links are complicated, and the time of transportation is too long, which leads to an increase in the total logistics cost. From the perspective of warehousing, the inventory information system of retail enterprises in my country is relatively backward, and the degree of informatization is not high. It is prone to goods overstock and slow sales. Most retail stores will eventually use promotion, large clearance and other methods to relieve inventory pressure, but these measures not only reduced the profit of the goods but also increased inventory costs ${ }^{[7]}$.

\section{Solutions to the cost management problems of new retail enterprises}

In China, new retail enterprises must reasonably solve the cost management problems they face in the development process, so as to promote the healthy development of the physical retail industry under the new retail format.

\subsection{Reducing labor costs}

\subsubsection{Improving the talent training mechanism and increase the future talent pool}

For new retail companies to develop online sales channels, the quality and skill levels of their employees need to be followed up simultaneously. The first thing for employees to do is to understand the computer network and learn Internet technology, so as to make it possible to deal with the daily affairs of the company through information technology in the future. Nowadays, the group that is most familiar with the Internet is college students. They are more 
willing to get in touch with new things and are more capable of learning new things. Therefore, it is necessary for enterprises to cultivate more college students through cooperation with universities. Wal-Mart's intern system is a good example. In 2020, when the epidemic was spreading, the employment situation for college students is even more difficult, and many college graduates are struggling to find jobs ${ }^{[8]}$. If companies can cooperate with universities and obtain a large number of college student resources, then high-quality and cheap interns can save lot of labor costs for retail companies. Moreover, companies can also "wash the sand in the waves" and select good interns to carry out key training, which also saves the company's recruitment costs.

\subsubsection{Implementing equity incentive policies to maximize employee value creation}

The average salary level of employees in new retail companies is very high, but high salary is not the only factor that motivates employees to maximize their work potential. Therefore, while paying high labor costs, companies also need to maximize returns and profits, that is, let employees create greater value for the company ${ }^{[9]}$. The equity incentive policy can well improve the enthusiasm and loyalty of employees. By acquiring part of the company's equity, employees obtain corresponding economic rights, enabling them to participate in company decision-making, share dividends, assume responsibilities and fulfill shareholders' obligations, and actively create higher value for the company. From employees to shareholders, from agents to partners, the change of employees' status will have a positive impact on their work mentality, prompting them to work harder to do their jobs and protect corporate interests from harm. This can not only reduce the labor cost burden of the enterprise, but also reduce the rate of brain drain.

\subsection{Reducing operating costs}

\subsubsection{Establishing enterprise cost management monitoring center}

The initial capital investment of new retail companies is inevitable, but we can do a careful calculation on top of the established costs. Establishing an enterprise cost management and monitoring center to reasonably manage and control various costs of the enterprise and propose optimization plans and suggestions for improvement. The cost management monitoring center clarifies the responsibilities of each department by formulating norms and standards, and regularly records and analyzes the cost control situation of each department, finds out the shortcomings and develops corresponding solutions. Penalties are imposed on departments or employees that have breached their duties. Through the rolling cycle of analysis, optimization, execution, and re-analysis, we can achieve the goal of continuously reducing business operating costs can be achieved.

\subsubsection{Choosing the right partner}

Improving the efficiency of resource allocation by selecting suitable partners is also one of the ways to duce business operating costs. In actual production and life, the acquisition of resources requires corresponding costs, but the combination of resources can achieve zero-cost expenditure. Enterprises should establish their own optimal resource allocation combination to maximize resource utilization and create additional benefits. The improvement of the efficiency of resource allocation helps to realize quality change, efficiency change and power change, which invisibly reduces the operating cost of the enterprise.

\subsection{Reducing logistics costs}

\subsubsection{Reasonably adopting various logistics distribution modes to reduce transportation costs}

Enterprises can carry out logistics distribution through three modes: namely self-built logistics, third-party logistics and logistics alliance. The choice of logistics mode determines the effect of logistics cost control. Enterprises can switch on various modes according to different distribution locations, that is, comprehensively utilize various logistics modes to control logistics costs while reducing logistics risks, reducing return rates, and meeting different consumer needs of customers. For example, JD.com has not only established its own logistics system, but also cooperated with third-party logistics to establish a comprehensive, systematic and efficient modern logistics system across the country to ensure the quality and speed of products in the delivery process. In order to meet customer needs, which not only effectively reduces the risk of self-built logistics system, but also greatly reduces the pressure on transportation costs ${ }^{[10]}$.

\subsubsection{Establishing an online reservation system to reduce inventory costs}


They can establish an online reservation system, such as the development of WeChat mini-programs. Before the sales department purchases from suppliers, first let users place orders online, and at the same time obtain market forecast demand through data analysis, and finally combine the two to form a final The order is sent to the supplier for goods purchase. By adding such a link, the needs of users can be met to a greater extent. At the same time, because it is booked in advance, the purchase data can be known in advance, which can well solve the problems of warehouse product surplus and goods backlog, achieving the purpose of reducing inventory costs.

\section{Concluding remarks}

In the context of consumption upgrades, consumers' sense of sovereignty is gradually awakening. New retail companies that want to provide customers with lower prices, faster speeds and more consumer choices must reduce costs and improve efficiency. In the cost of various expenditures, the largest proportion is nothing more than labor costs, operating costs and logistics costs. Enterprises need to continuously explore, seek more cost management solutions, establish efficient cost management models, and realize online and offline integration supported by information technology and logistics services. Only in this way can enterprises better adapt to the development needs of the new era, gain a firm foothold and grow stronger in the complex industry competition.

\section{References}

1. Xiao B, Dong C. Ununmanned retail form and development trend from the changing perspective of "New Retail" (in Chinese). Journal of Business Economics 2019; (03): 32 - 34.

2. $\mathrm{Su}$ C, De W. Journal of Hubei University of Technology (in Chinese) 2019; 34(06): $45-48$.

3. Chan L. A brief discussion on the cost control of the transformation from traditional small and mediums retail enterprises to new retail enterprises (in Chinese). China Township Enterprise Accounting 2020; (04): 140 - 141.

4. Jing L. Research on cost control of L retail enterprises under omni-channel retail mode (in Chinese). Henyang University 2020.

5. Jun L. Cost accounting management of chain retail enterprises from the perspective of value chain (in Chinese). Chinese \& Foreign Entrepreneurs 2018; (30): 19.

6. Xiao L. Development status, problems and countermeasures of new retail in China (in Chinese). Information Communication Technology and Policy 2019; (03): 35-37.

7. Yu T. Discussion on the problems and countermeasures in the development of new retail (in Chinese). Modern Marketing (next issue) 2018; (08): 99.

8. Jun W. Equity incentive: a "rare product" that ignites employees' passion — on how to do equity incentive in non-listed companies (in Chinese). Human Resources 2009; (12): 38-41.

9. Hong X, Nan L, Biao X, et al. Research on the cost control path of bricks-and-mortar retail transformation to new retail in Chinese). Times Finance 2018; (15): 203-205.

10. Yang Z. Research on Enterprise Cost Control Based on New Retail Mode (in Chinese). Zhongyuan University of Technology 2019. 